\title{
A novel TLR-8 agonist attenuates nasal symptoms/congestion in both dog and human allergen challenge studies
}

\author{
Edward G Barrett ${ }^{1 *}$, Karin Rudolph ${ }^{1}$, Maura Matthews ${ }^{2}$, Greg Dietsch², Robert Hershberg ${ }^{2}$ \\ From 2nd Cross Company Respiratory Symposium \\ Horsham, UK. 6-7 September 2012
}

\section{Rationale}

VTX-378/1463 are selective TLR8 agonists that interact with monocytes, macrophages, and myeloid dendritic cells. We hypothesized that delivery of VTX via nasal spray directly to sites of allergic inflammation might initiate rapid anti-allergic activity.

\section{Methods}

(Dog) Ragweed (RW)-sensitized dogs $(\mathrm{n}=5)$ were treated with VTX-378 $(100,500$ or $1000 \mu \mathrm{g} / \mathrm{dog})$, given $\sim 24$ hours prior to RW challenge. Two VTX-378 pretreatments of 250 or $1000 \mu \mathrm{g} / \mathrm{dog}$, spaced either 3 , 4 or 7 days apart were also evaluated. Changes in nasal cavity volumes (congestion) were determined by acoustic rhinometry. (Human) Subsequently, a randomized, double blind, placebo-controlled study was conducted in-season, and enrolled 80 adults with confirmed atopy to grass pollen. Two dosing regimens were compared to placebo: ascending dose (GrpA; 25, 50, 75, $100 \mu \mathrm{g}$ ) and fixed dose (GrpB; $62.5 \mu \mathrm{g} \times 4$ doses). Subjects were dosed on Days 1, 8, 15, and 22 with VTX-1463. On day 24, subjects underwent grass allergen exposure. The primary endpoints were the average change over 6 hours of allergen exposure in Total Nasal Symptom Score (TNSS; sum of scores for nasal congestion, itching, sneezing and rhinorrhea) and Active Anterior Rhinometry (ARR).

\section{Results}

(Dog) Statistically significant improvements in nasal congestion $(44.5 \% \pm 8.7 \%, 59.1 \% \pm 15.1 \%$ and $56.5 \% \pm 10.0 \%$ increase in nasal cavity volume $v s$ vehicle) were seen at 100, 500 and $1000 \mu \mathrm{g} / \mathrm{dog}$ doses, respectively, following
24 hour pretreatment. Two $250 \mu \mathrm{g} / \mathrm{dog}$ doses at Day -4 and Day -1, resulted in efficacy comparable to a single $500 \mu \mathrm{g} / \mathrm{dog}$ dose given at Day $-1(58.9 \% \pm 10.3 \%$ versus $59.1 \% \pm 15.1 \%)$. At a dose of $1000 \mu \mathrm{g} / \mathrm{dog}$, VTX-378, pretreatment on Days -8 and -1 , Days -5 and -1 or only Day -1 significantly attenuated nasal congestion $(71.9 \% \pm$ $7.7 \%, 65.4 \% \pm 10.3 \%$ and $56.5 \% \pm 10.0 \%$, respectively). (Human) Significant improvements in TNSS were observed in both $\operatorname{GrpA}(\mathrm{p}=0.008)$ and $\operatorname{GrpB}(\mathrm{p}=0.012)$. AAR trended towards a benefit in both groups but did not reach statistical significance.

\section{Conclusions}

Overall, VTX conferred clinical benefit in a dose-dependent manner in both the preclinical dog allergen challenge model and the human allergen challenge chamber studies. These findings suggest that in the context of nasal allergies the dog model can be predictive of dose and clinical efficacy.

\section{Authors' details \\ 'Lovelace Respiratory Research Institute, Albuquerque, NM, 87108, USA. ${ }^{2}$ VentiRx Pharmaceuticals, Inc., Seattle, WA, USA.}

Published: 14 August 2013

doi:10.1186/1476-9255-10-S1-P14

Cite this article as: Barrett et al:: A novel TLR- 8 agonist attenuates nasal symptoms/congestion in both dog and human allergen challenge studies. Journal of Inflammation 2013 10(Suppl 1):P14.

* Correspondence: tbarrett@|rri.org

'Lovelace Respiratory Research Institute, Albuquerque, NM, 87108, USA

Full list of author information is available at the end of the article

(c) 2013 Barrett et al; licensee BioMed Central Ltd. This is an Open Access article distributed under the terms of the Creative Commons Attribution License (http://creativecommons.org/licenses/by/2.0), which permits unrestricted use, distribution, and reproduction in any medium, provided the original work is properly cited. 